\title{
Effect of Chloride on Tensile and Bending Capacities of Basalt FRP Mesh Reinforced Cementitious Thin Plates under Indoor and Marine Environments
}

\author{
Yan Xie, Kunhua Guan, and Lin Lai \\ School of Civil and Transportation Engineering, Guangdong University of Technology, Guangzhou 510006, China \\ Correspondence should be addressed to Yan Xie; xieyan@gdut.edu.cn
}

Received 23 September 2016; Accepted 9 November 2016

Academic Editor: Baolin Wan

Copyright (C) 2016 Yan Xie et al. This is an open access article distributed under the Creative Commons Attribution License, which permits unrestricted use, distribution, and reproduction in any medium, provided the original work is properly cited.

\begin{abstract}
This paper presented a durability experimental study for thin basalt fiber reinforced polymer (BFRP) mesh reinforced cementitious plates under indoor and marine environment. The marine environment was simulated by wetting/drying cycles (wetting in salt water and drying in hot air). After 12 months of exposure, the effects of the chloride on the tensile and bending behaviors of the thin plate were investigated. In addition to the penetration of salt water, the chloride in the thin plate could be also from the sea sand since it is a component of the plate. Experimental results showed that the effect of the indoor exposure on the tensile capacity of the plate is not pronounced, while the marine exposure reduced the tensile capacity significantly. The bending capacity of the thin plates was remarkably reduced by both indoor and marine environmental exposure, in which the effect of the marine environment is more severe. The tensile capacity of the meshes extracted from the thin plates was tested, as well as the meshes immersed in salt solution for 30,60, and 90 days. The test results confirmed that the chloride is the reason of the BFRP mesh deterioration. Moreover, as a comparison, the steel mesh reinforced thin plate was also tested and it has a similar durability performance.
\end{abstract}

\section{Introduction}

Basalt fiber reinforced polymer (BFRP) is a new type of composite material with high performance and relatively low cost. It has good durability and chemical stability as well as excellent electrical insulation, fire resistance, and thermal resistance [1-3]. Recently, BFRP has been developed for some applications in civil engineering $[4,5]$. As a nonmetallic material, furthermore, BFRP has become an attractive alternative to steel in the structures subjected to marine environment [6-8]. The BFRP tendons showed superior resistance to salt corrosion [9], while the bond strength of the BFRP bars embedded in concrete exposed to a long-term chloride environment decreased remarkably. In addition, some studies had shown that the concrete pore alkaline solution can affect the durability of BFRP, which can reduce the bonding strength between the BFRP bar and concrete $[10,11]$.

Because of the reduction in available river sand and development of ocean engineering, the exploration and utilization of sea sand resources have been gaining increased attention.
The chloride present in sea sand threatens the durability of concrete structures containing it, thereby limiting its application [12]. Currently, there are two main approaches to maximize the utilization of sea sand: after washing and direct usage. Because of the high cost and low efficiency of the former approach, direct usage will be the predominant approach in the future. Yin et al. [13] indicated that longer curing times, less water consumption per cubic meter, and a smaller water/cement ratio can effectively reduce the chloride ion penetration and improve the durability of the concrete. To avoid steel corrosion by the chloride, nevertheless, many studies had considered using FRP materials to replace steel [14-16]. Dong et al. [17] investigated the durability performance of steel-BFRP composite bars in sea sand concrete.

Deng and Lee [18] reported a steel mesh reinforced cementitious thin plate. Based on the study, the authors [19] further presented an innovative thin plate with BFRP mesh and sea sand instead of steel mesh and river sand, respectively. The initial flexural toughness and flexural bearing capacity were better than those of the steel mesh thin plate. Although 
the BFRP sheet and bar exhibited high resistance to chloride corrosion, the degradation of BFRP mesh needs to be investigated. Because of the differences among the mesh, sheet, and bar in production technology, the matrix types and fiber volume fraction can affect the durability performance of BFRP [9].

To date, no particular study on the effect of the chloride on the mechanical properties of the BFRP mesh as well as its reinforced thin plate can be found. This paper conducted an experimental study on the durability of the BFRP mesh reinforced sea sand cementitious thin plates under indoor and marine environments. Mechanical behaviors of the thin plates as well as the BFRP mesh were tested after environmental exposure. In addition, for comparison, the specimens of steel mesh reinforced thin plate were tested in the same procedures.

\section{Experimental Study}

2.1. Materials. The mix proportions of sea sand mortar were $1: 2.23: 0.012: 0.45$ (cement : sea sand : superplasticizer : water). The particles of the sea sand were filtered in the range of $0.063-0.355 \mathrm{~mm}$. Portland cement used was P.O 42.5. The superplasticizer had a water reduction rate of $\geq 38 \%$. The sea sand mortar has the advantages of high density, low water absorption, and high compressive and flexural strengths.

For comparison, two types of mesh, BFRP mesh and steel mesh with a grid size of $10 \mathrm{~mm} \times 10 \mathrm{~mm}$, were used. The test procedures of the fiber and steel were carried out according to Chinese standard (GB/T3362-2005) [20]. The linear density and the density of fiber bundle of BFRP mesh were $800 \mathrm{~g} / \mathrm{km}$ and $2.65 \mathrm{~g} / \mathrm{cm}^{3}$, respectively. Therefore, the section area of the fiber bundle was $0.3 \mathrm{~mm}^{2}$. The ultimate tensile capacity and ultimate elongation of fiber were $291.5 \mathrm{~N}$ and $1.8 \%$, respectively. The ultimate strength and elastic modulus of BFRP bundle were $970 \mathrm{MPa}$ and $100 \mathrm{GPa}$, respectively. The diameter and section area of the steel wire were $0.7 \mathrm{~mm}$ and $0.38 \mathrm{~mm}^{2}$, respectively. The yield strength and elastic modulus of wire were $300 \mathrm{MPa}$ and $200 \mathrm{GPa}$, respectively.

2.2. Environmental Conditions. Three environmental conditions were considered. Condition (I) represents no environmental exposure, under which the control specimens were tested just after 28-day curing. Condition (II) represents exposure to natural indoor environment for 12 months. Condition (III) represents exposure to the marine environment for 12 months. The marine environment was produced by placing specimens in a salt solution under wetting/drying cycles. Each wetting/drying cycle was $24 \mathrm{~h}$. The specimens were immersed in a $3.5 \% \mathrm{NaCl}$ solution for $10 \mathrm{~h}$, following by drying at $40^{\circ} \mathrm{C}$ for $14 \mathrm{~h}$. The temperature control accuracy is $\pm 1^{\circ} \mathrm{C}$.

2.3. Specimens of Thin Plate. The thin plates were fabricated in the wooden molds with the dimensions of $800 \mathrm{~mm} \times$ $150 \mathrm{~mm} \times 8 \mathrm{~mm}$, as shown in Figure 1. Two layers of BFRP or steel meshes were placed in the mold and fixed. After
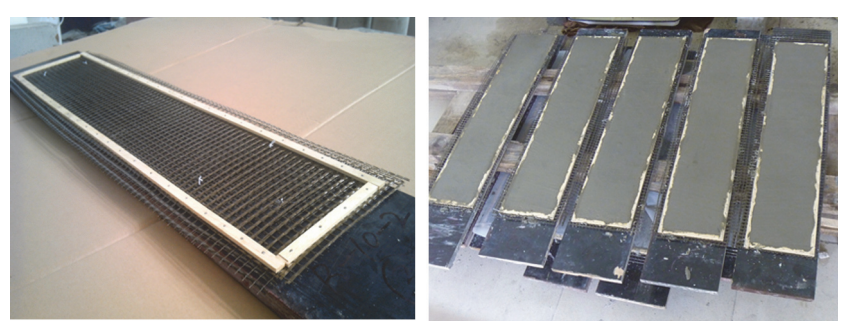

FIgURE 1: Molds of thin plates.

TABLE 1: Details of specimens.

\begin{tabular}{|c|c|c|c|}
\hline $\begin{array}{l}\text { Specimens of } \\
\text { tensile test }\end{array}$ & $\begin{array}{l}\text { Specimens of } \\
\text { bending test }\end{array}$ & $\begin{array}{c}\text { Reinforced } \\
\text { mesh }\end{array}$ & $\begin{array}{c}\text { Environmental } \\
\text { condition }\end{array}$ \\
\hline $\mathrm{T}-\mathrm{B}(\mathrm{I})$ & M-B(I) & BFRP mesh & $\begin{array}{c}\text { Without } \\
\text { exposure }\end{array}$ \\
\hline T-B(II) & M-B(II) & BFRP mesh & $\begin{array}{c}\text { Indoor for } 12 \\
\text { months }\end{array}$ \\
\hline T-B(III) & M-B(III) & BFRP mesh & $\begin{array}{c}\text { Marine for } 12 \\
\text { months }\end{array}$ \\
\hline $\mathrm{T}-\mathrm{S}(\mathrm{I})$ & M-S(I) & Steel mesh & $\begin{array}{l}\text { Without } \\
\text { exposure }\end{array}$ \\
\hline T-S(II) & M-S(II) & Steel mesh & $\begin{array}{c}\text { Indoor for } 12 \\
\text { months }\end{array}$ \\
\hline T-S(III) & M-S(III) & Steel mesh & $\begin{array}{c}\text { Marine for } 12 \\
\text { months }\end{array}$ \\
\hline
\end{tabular}

being cast with mixed mortar, the specimens were vibrated and then the surfaces were smoothed. The specimens were cured at $20^{\circ} \mathrm{C}$ and $\mathrm{RH}>95 \%$ for 28 days. Specimens for tensile test were cut into the dimensions of $150 \mathrm{~mm} \times$ $50 \mathrm{~mm}$ [18], containing ten bundles or wires in longitudinal direction. Specimens for bending test were cut into the dimensions of $700 \mathrm{~mm} \times 150 \mathrm{~mm}$ according to Chinese standard (GB/T19631-2005) [21].

Table 1 summarizes all the thin plate specimens. The references " $T$ " and " $M$ " indicate tensile test and bending test, respectively. "B" and "S" mean BFRP mesh and steel mesh, respectively. The Roman numerals (I), (II), and (III) represent the environmental conditions.

2.4. Tensile and Bending Tests. The tensile and bending tests were carried out in a DDL100 electronic universal testing machine. The two ends of the tensile specimens treated with epoxy resin were fixed in two clamps at $60 \mathrm{~mm}$ spacing, respectively, as shown in Figure 2. The load was applied at a constant rate of $0.2 \mathrm{~mm} / \mathrm{min}$ during the tensile tests. As shown in Figure 3, the ends of bending specimens were fixed in a G-type clamping device to simulate the fixed ends in the bending test. Three-point bending with a clear span of $500 \mathrm{~mm}$ was carried out at a constant rate of $2 \mathrm{~mm} / \mathrm{min}$. The data of the load and displacement was automatically recorded by the testing machine.

2.5. Tensile Test of Mesh. Two series of meshes were tested. (1) BFRP bundles or steel wires were obtained from the meshes in the thin plates exposed to the indoor and marine 


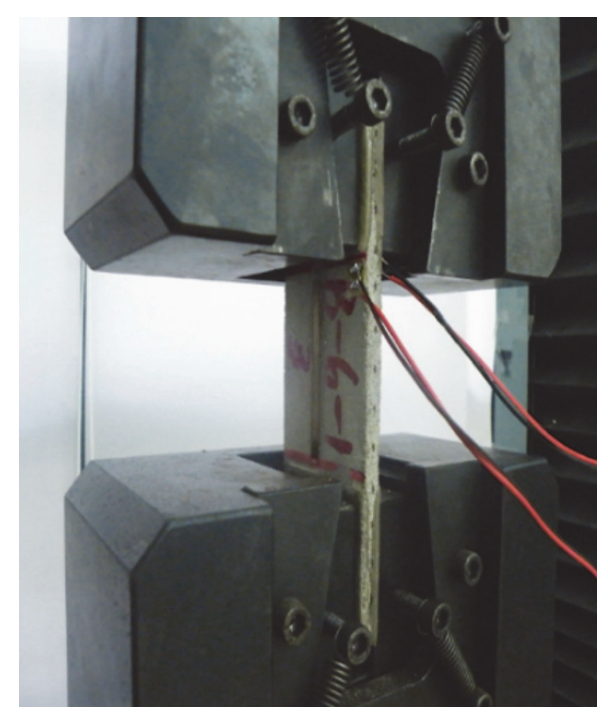

FIGURE 2: Tensile test of thin plate.

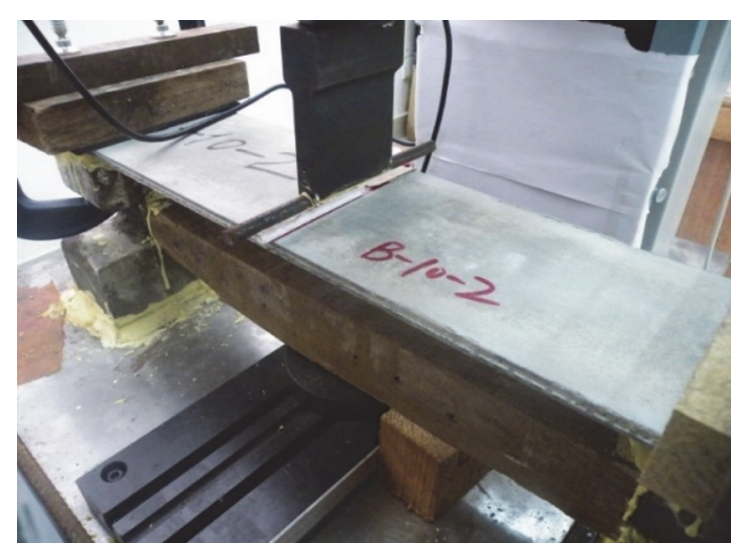

FIGURE 3: Bending test of thin plate.

environments; (2) BFRP bundles or steel wires obtained from the sound meshes were immersed in saturated $\mathrm{NaCl}$ solution for $30 \mathrm{~d}, 60 \mathrm{~d}$, and $90 \mathrm{~d}$ and thereafter were vacuum-dried after washing by distilled water. After measuring the mass loss, the BFRP bundles and steel wires were tensile-tested according to Chinese standard (GB/T 3362-2005) [20]. The clear length of the specimens is $150 \mathrm{~mm}$, as shown in Figure 4.

\section{Results}

3.1. Tensile Capacity of Thin Plates. The load-displacement curves obtained from the tensile tests of the thin plates were shown in Figures 5 and 6 . The curves can be divided into three stages. The first stage is the linear ascent segment, during which the tensile force was mainly carried by the mortar and no crack was observed on the thin plates. During the second stage, the cracks continually developed and the tensile force carried by the bundles or wires increased gradually. During the third stage, the bundles or wires carried the tensile force individually until the specimens failed.
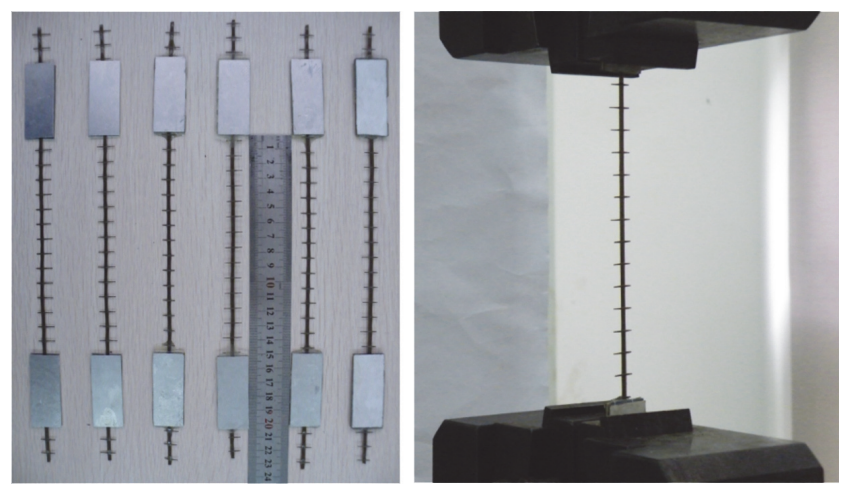

FIGURE 4: Specimens and tensile test of BFRP bundle.

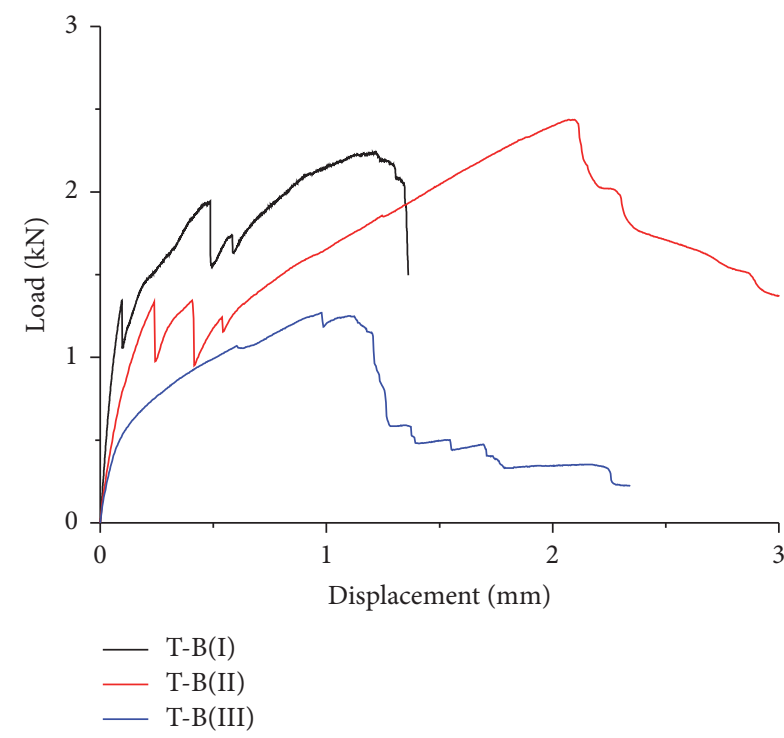

FIGURE 5: Load-displacement curves of specimens T-B.

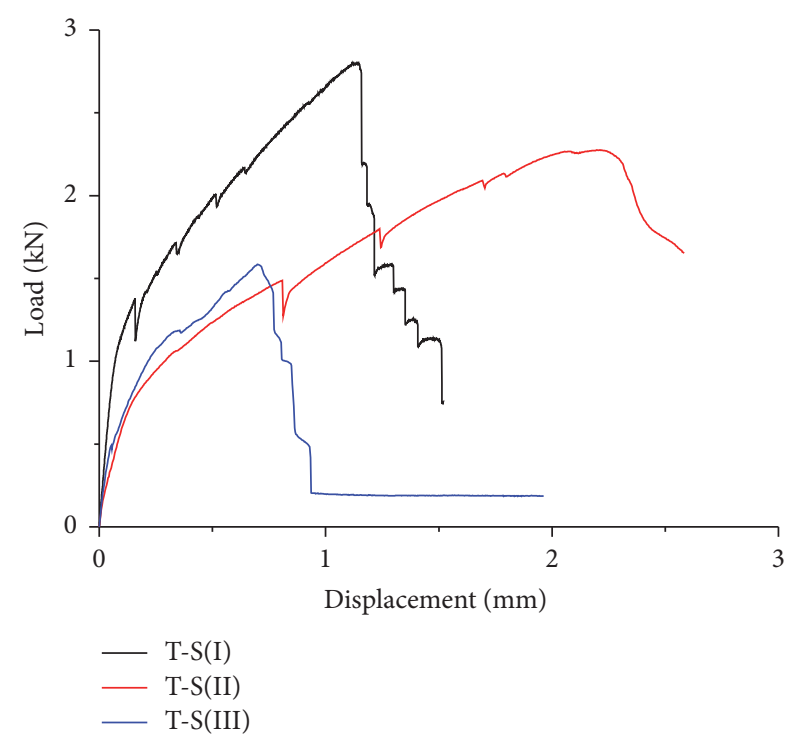

Figure 6: Load-displacement curves of specimens T-S. 
TABLE 2: The results of tensile tests.

\begin{tabular}{lcc}
\hline Specimen & Cracking load $F_{r}(\mathrm{kN})$ & Failure load $F_{u}(\mathrm{kN})$ \\
\hline T-B(I) & 1.34 & 2.24 \\
T-B(II) & 1.34 & 2.43 \\
T-B(III) & 0.47 & 1.26 \\
T-S(I) & 1.38 & 2.80 \\
T-S(II) & 1.47 & 2.27 \\
T-S(III) & 0.50 & 1.58 \\
\hline
\end{tabular}

Because the load was mainly borne by the mortar in the first stage of the tensile test, the first cracking loads of $\mathrm{B}(\mathrm{II})$ and $\mathrm{B}(\mathrm{I})$ were almost the same. However, the BFRP was corroded by the high alkalinity of cement, which deteriorated the interface and affected the integrity of the fiber bundles. Because of this, relative slip occurred between the fibers during the tensile and bending tests, which led to larger ultimate displacement of B(II) and B(I) as shown in Figure 5.

As shown in Figures 5 and 6 , the ultimate displacement of specimens $\mathrm{T}-\mathrm{B}(\mathrm{II})$ and $\mathrm{T}-\mathrm{S}(\mathrm{II})$ under indoor condition was larger than of the specimens under two other environmental conditions. Meanwhile, the ultimate displacement of specimens $\mathrm{T}-\mathrm{B}$ (III) and T-S(III) was the minimum, which showed that the marine environment has an extensive effect on the ductility of the thin plate. In addition, BFRP thin plates showed better ductility than steel thin plates under the same conditions.

The cracking loads and failure loads of the tensile tests were recorded in Table 2. As shown in the table, the cracking loads between specimens T-B(I) and T-B(II) as well as TS(I) and T-S(II) were close. Meanwhile, the differences of the failure loads obtained from the specimens under conditions (I) and (II) were not pronounced. However, the cracking load and failure load of specimen T-B(III) showed significant decline of $53 \%$ and $43.8 \%$, respectively. The cracking load and failure load of specimen T-s(III) showed significant decline of $63.8 \%$ and $58 \%$, respectively.

3.2. Bending Capacity of Thin Plate. The bending loaddeflection curves were shown in Figures 7 and 8. In terms of the testing process, the curves can be divided into three stages. The first one was the elastic stage until crack initiated. During the second stage, the microcracks developed in the thin plate until a macrocrack appeared. During the third stage, the bending loading was gradually carried by the meshes until the plate failed.

The cracking loads, failure loads, and ultimate deflections of the bending tests were recorded in Table 3. Compared with $\mathrm{B}(\mathrm{I})$, the cracking and failure loads of $\mathrm{B}(\mathrm{II})$ declined by $33.8 \%$ and $44 \%$, whereas those of B(III) decreased by $49.6 \%$ and $79 \%$, respectively. Compared with S(I), the cracking and failure loads of S(II) decreased by $42 \%$ and $21.5 \%$, whereas those of S(III) decreased by $56.1 \%$ and $44.2 \%$, respectively. The environmental exposure clearly had a more significant effect on the failure load of the BFRP thin plates than the steel mesh thin plates. The ultimate deflections were affected by the conditions as well. The ultimate deflections of both

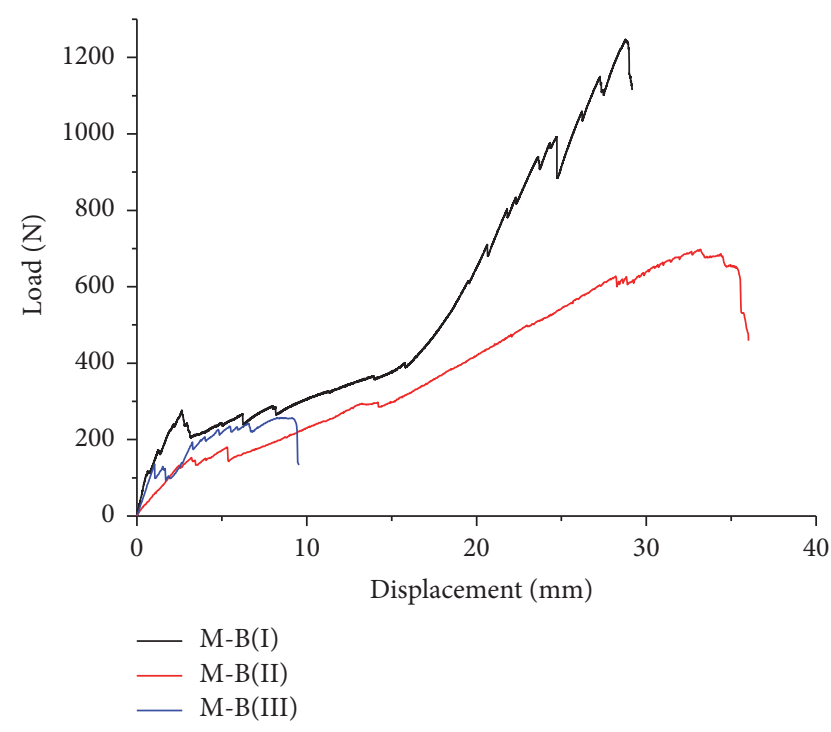

FIgURE 7: Load-displacement curves of specimens M-B.

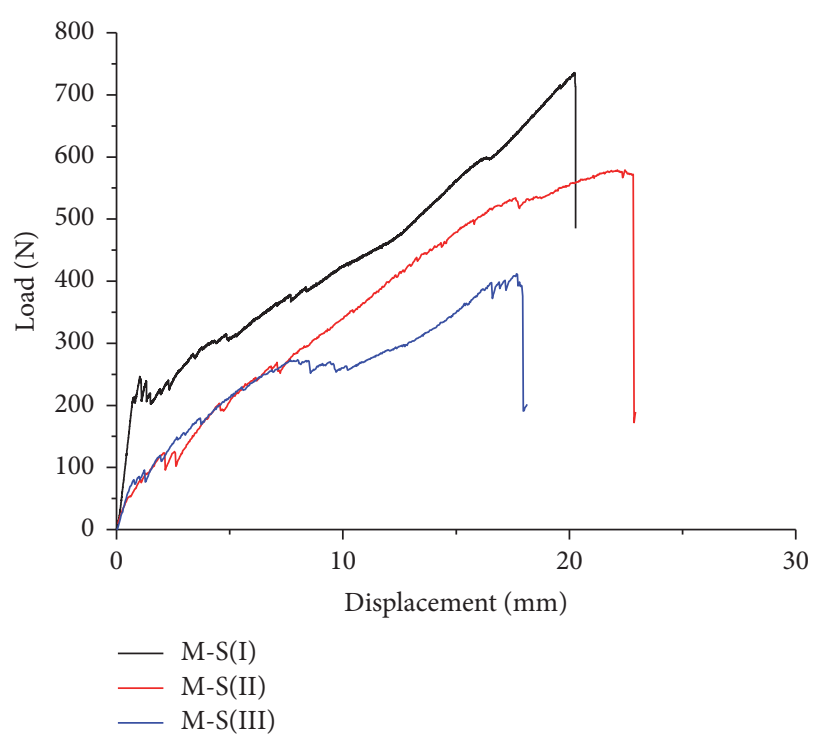

FIgURE 8: Load-displacement curves of specimens M-S.

the BFRP and the steel mesh thin plates increased slightly under condition (II), while they decreased remarkably under condition (III). In particular, the ultimate deflection of B(III) was only $9 \mathrm{~mm}$.

The fracture surfaces of the thin plates failed by bending tests were shown in Figure 9. Small pores were observed on the interfaces between the mortar and BFRP bundles in Figures 9(a) and 9(b), where the small pores were more significant under marine environment (Figure 9(b)) than under indoor environment (Figure 9(a)). In Figure 9(d), corrosion of the steel meshes was obvious, while the pores were not pronounced. This demonstrated that the reduction of the failure load of M-S(III) was lower than that of M-B(III). 


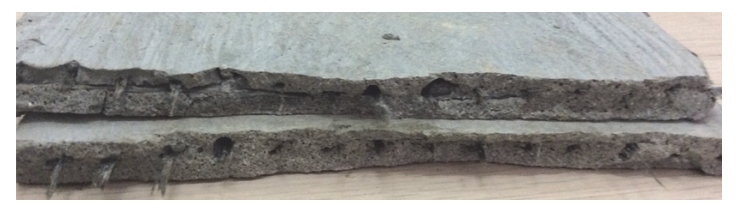

(a) $\mathrm{M}-\mathrm{B}(\mathrm{II})$

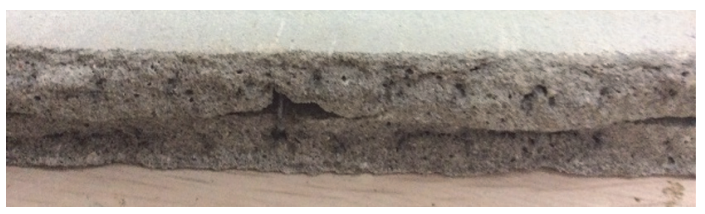

(c) $\mathrm{M}-\mathrm{S}(\mathrm{II})$

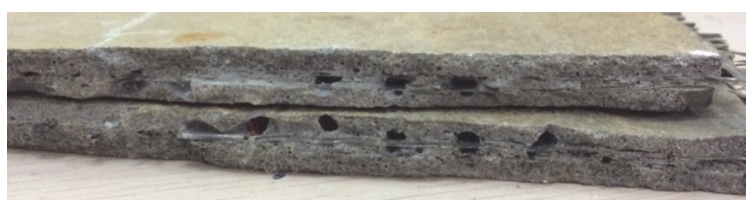

(b) M-B(III)

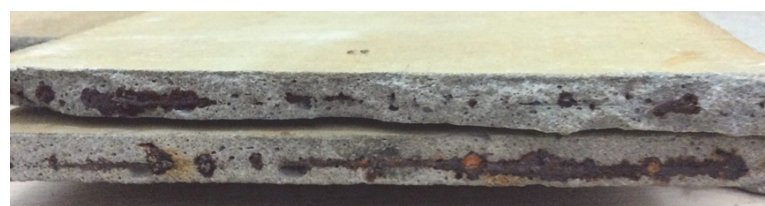

(d) $\mathrm{M}-\mathrm{S}(\mathrm{III})$

FIGURE 9: Fracture surfaces of the thin plates failed by bending tests.

TABLE 3: The results of bending test.

\begin{tabular}{lccc}
\hline Specimen & $\begin{array}{c}\text { Cracking load } \\
P_{r}(\mathrm{~N})\end{array}$ & $\begin{array}{c}\text { Failure load } P_{u} \\
(\mathrm{~N})\end{array}$ & $\begin{array}{c}\text { Ultimate deflection } \\
D(\mathrm{~mm})\end{array}$ \\
\hline M-B(I) & 272 & 1249 & 28.7 \\
M-B(II) & 180 & 697 & 33.1 \\
M-B(III) & 137 & 257 & 9.0 \\
M-S(I) & 212 & 734 & 20.3 \\
M-S(II) & 123 & 576 & 22.8 \\
M-S(III) & 93 & 409 & 17.7 \\
\hline
\end{tabular}

TABLE 4: Tensile capacity of the bundles and wires.

\begin{tabular}{lcc}
\hline Specimens & Failure load $P(\mathrm{kN})$ & Ultimate elongation (\%) \\
\hline BFRP-C & 0.34 & 7.3 \\
BFRP-B(II) & 0.26 & 4.2 \\
BFRP-B(III) & 0.14 & 1.9 \\
Steel-C & 0.35 & 5.1 \\
Steel-S(II) & 0.22 & 2.4 \\
Steel-S(III) & 0.15 & 1.6 \\
\hline
\end{tabular}

Note. References "BFRP-C" and "Steel-C" indicate the BFRP bundle and steel wires directly obtained from sound meshes, respectively, while the others indicate the BFRP bundle or steel wires extracted from thin plates after environmental exposure.

3.3. Tensile Test Results of the Mesh from Thin Plates. The tensile capacities of the mesh extracted from the thin plates were recorded in Table 4. Compared with the control specimen "BFRP-C," the failure load and ultimate elongation of BFRPB(II) decreased by $25 \%$ and $42.5 \%$, whereas those of BFRPB(III) declined by $58.3 \%$ and $73.9 \%$. This indicated that BFRP meshes were seriously corroded after the environmental exposure, especially the marine environmental exposure. Besides, the steel wires had similar durability performance. These results demonstrated that the chloride from the sea sand in the plates as well as that penetrated from the outside salt water has a significant effect on BFRP bundles and steel wires.

Since only meshes carried the tensile load when the thin plate failed, the theoretical tensile failure load of the plates

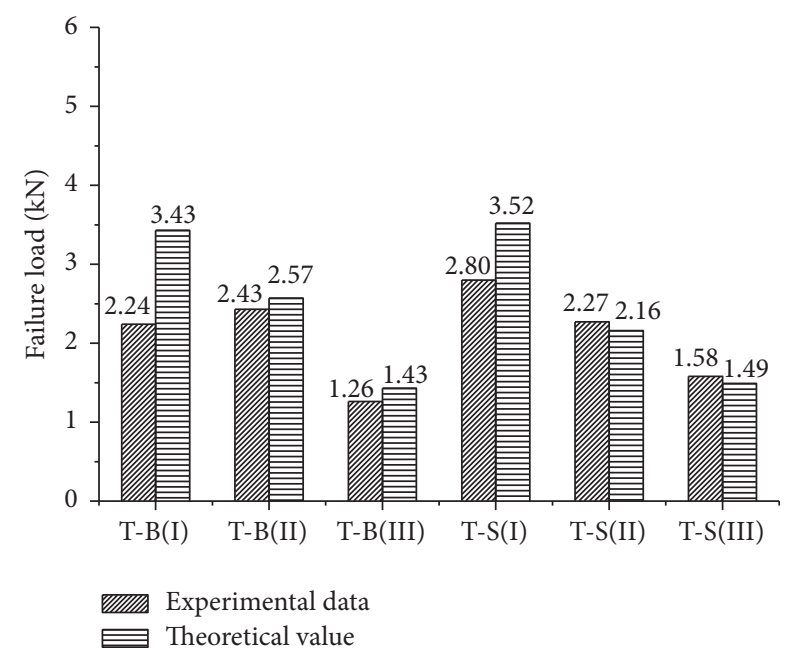

FIGURE 10: Comparisons of the tensile failure loads of the thin plates.

can be evaluated by the tensile capacity of the bundles or wires. The thin plate specimens had 10 bundles or wires in the longitudinal direction; therefore, the theoretical tensile failure loads of the plates were equal to 10 times the tensile capacity of the bundles or wires, which were compared with experimental results in Figure 10. The experimental and theoretical results of the thin plates exposed to environmental conditions, T-B(II), T-B(III), T-S(II), and T-S(III), were very close, which confirmed that the meshes carried most of the failure loads. The experimental results of T-B(I) and T-S(I) were obviously lower than those of theoretical results. This is because the specimens BFRP-C and Steel- $\mathrm{C}$ were obtained from the sound meshes and not from the meshes extracted from the plates. This indicated that the chloride contained in sea sand can corrode both BFRP and steel even just after 28 days of curing [22].

3.4. Influence of Chloride on BFRP and Steel Wire. The mass loss rates and failure loads of the bundles and wires were recorded in Table 5. As shown in the table, the mass loss rate of both BFRP and steel increased with the days of immersing 
TABLE 5: Mass loss rate and failure load of bundles after being placed in $\mathrm{NaCl}$ solution.

\begin{tabular}{lcccc}
\hline \multirow{2}{*}{ Time (day) } & \multicolumn{2}{c}{ Mass loss rate (\%) } & \multicolumn{2}{c}{ Failure load (kN) } \\
& BFRP bundle & Steel wire & BFRP bundle & Steel wire \\
\hline 0 & 0 & 0 & 0.29 & 0.52 \\
30 & 2 & 0.08 & 0.29 & 0.26 \\
60 & 3 & 9 & 0.24 & 0.15 \\
90 & 11 & 40 & 0.1 & 0.07 \\
\hline
\end{tabular}

in the $\mathrm{NaCl}$ solution, while the tensile capacity decreased. Particularly, the tensile capacity of the BFRP bundles reduced by $65.5 \%$ after being immersed in $\mathrm{NaCl}$ solution for 90 days; this indicated that chloride causes BFRP deterioration significantly. In addition, both the mass loss rates and the failure loads of the BFRP bundles varied slightly during a period of 0-60 days, while they decreased significantly during a period of 60-90 days. This indicated that the degradation of mechanical property is consistent with the mass loss. $\mathrm{Fe}$ element existing in the former with mainly $\mathrm{Fe}^{2+}$ in BFRP [23] can react with $\mathrm{Cl}^{-}$. The final product of this chemical reaction was $\mathrm{Fe}_{2} \mathrm{O}_{3} \cdot n \mathrm{H}_{2} \mathrm{O}$ which can absorb $\mathrm{H}_{2} \mathrm{O}$ and expand the matrix of BFRP. As a result, microcracks initiated in BFRP fibers and weakened their mechanical performance. Meanwhile, some components in BFRP, such as $\mathrm{Ca}, \mathrm{Mg}, \mathrm{Al}$, and $\mathrm{K}$, dissolved in the solution, resulting in mass loss.

\section{Conclusions}

This paper studied the durability of the BFRP mesh reinforced sea sand cementitious thin plates under indoor and marine environments for 12 months. Mechanical behaviors of the thin plates and the BFRP mesh were tested. As a comparison, steel mesh reinforced thin plate was investigated as well. The following conclusions can be drawn from the experimental results:

(1) The indoor exposure on the tensile capacity of the BFRP mesh reinforced cementitious thin plate is not pronounced, while the marine exposure reduced the tensile capacity by $43.8 \%$.

(2) After exposure to the indoor and marine environments, the bending capacity of the BFRP thin plates was reduced by $49.6 \%$ and $79.0 \%$, respectively.

(3) The tensile capacity of the BFRP bundle extracted from thin plate under indoor and marine environments for 12 months decreased by $25.0 \%$ and $58.3 \%$.

(4) The tensile strength of the BFRP bundles reduced by $65.5 \%$ after being immersed in $\mathrm{NaCl}$ solution for 90 days, which confirmed that the chloride is the main cause of the BFRP mesh deterioration.

(5) The steel mesh reinforced cementitious thin plates have similar durability performance to the BFRP thin plates.

\section{Competing Interests}

The authors declare that there are no competing interests regarding the publication of this paper.

\section{Acknowledgments}

The authors thank the following groups for their financial support: the National Natural Science Foundation of China (nos. 51278131 and 51202036), New Century Outstanding Talent Support Program Project of China (NCET-13-0739), and Guangdong Provincial Education Department Project of China (2012LYM_0056).

\section{References}

[1] T. Zych and K. Wojciech, "Study on the properties of cement mortars with basalt fibres," Brittle Matrix Composites, vol. 10, pp. 155-166, 2012.

[2] V. A. Rybin, A. V. Utkin, and N. I. Baklanova, "Alkali resistance, microstructural and mechanical performance of zirconiacoated basalt fibers," Cement and Concrete Research, vol. 53, pp. $1-8,2013$.

[3] C. Jiang, K. Fan, F. Wu, and D. Chen, "Experimental study on the mechanical properties and microstructure of chopped basalt fibre reinforced concrete," Materials \& Design, vol. 58, no. 6, pp. 187-193, 2014.

[4] J. Sim, C. Park, and D. Y. Moon, "Characteristics of basalt fiber as a strengthening material for concrete structures," Composites Part B: Engineering, vol. 36, no. 6-7, pp. 504-512, 2005.

[5] J. Deng, T. Liu, W. Xie, and W. Lu, "Study on repaired earthquake-damaged bridge piers under seismic load," Advances in Materials Science and Engineering, vol. 2015, Article ID 295392, 10 pages, 2015.

[6] Z. Dong, G. Wu, B. Xu, X. Wang, and L. Taerwe, "Bond durability of BFRP bars embedded in concrete under seawater conditions and the long-term bond strength prediction," Materials \& Design, vol. 92, pp. 552-562, 2016.

[7] X. Wang, G. Wu, Z. Wu, Z. Dong, and Q. Xie, "Evaluation of prestressed basalt fiber and hybrid fiber reinforced polymer tendons under marine environment," Materials \& Design, vol. 64, pp. 721-728, 2014.

[8] G. Wu, Z.-Q. Dong, X. Wang, Y. Zhu, and Z.-S. Wu, "Prediction of long-term performance and durability of BFRP bars under the combined effect of sustained load and corrosive solutions," Journal of Composites for Construction, vol. 19, no. 3, Article ID 4014058, 2015.

[9] X. Wang, G. Wu, Z. Wu, Z. Dong, and Q. Xie, "Evaluation of prestressed basalt fiber and hybrid fiber reinforced polymer tendons under marine environment," Materials and Design, vol. 64, pp. 721-728, 2014.

[10] Y. Chen, J. F. Davalos, I. Ray, and H.-Y. Kim, "Accelerated aging tests for evaluations of durability performance of FRP reinforcing bars for concrete structures," Composite Structures, vol. 78, no. 1, pp. 101-111, 2007.

[11] A. Altalmas, A. E. Refai, and F. Abed, "Bond degradation of basalt fiber-reinforced polymer (BFRP) bars exposed to accelerated aging conditions," Construction and Building Materials, vol. 81, pp. 162-171, 2015.

[12] S. L. Amey, D. A. Johnson, M. A. Miltenberger, and H. Farzam, "Predicting the service life of concrete marine structures: an 
environmental methodology," ACI Structural Journal, vol. 95, no. 2, pp. 205-214, 1998.

[13] H. Yin, Y. Li, H. Lv, and Q. Gao, "Durability of sea-sand containing concrete: effects of chloride ion penetration," Mining Science and Technology, vol. 21, no. 1, pp. 123-127, 2011.

[14] R. Hempel, "Thin textile-reinforced concrete thin-walled panel material," Betonwerk and Fertigteil-Technik/Concrete Precasting Plant and Technology, vol. 63, no. 3, pp. 144-146, 1998.

[15] H. W. Reinhardt, M. Krüger, and C. U. Große, "Concrete prestressed with textile fabric," Journal of Advanced Concrete Technology, vol. 1, no. 3, pp. 231-239, 2003.

[16] M. Butler, V. Mechtcherine, and S. Hempel, "Durability of textile reinforced concrete made with AR glass fibre: effect of the matrix composition," Materials and Structures, vol. 43, no. 10, pp. 1351-1368, 2010.

[17] Z. Dong, G. Wu, and Y. Xu, "Experimental study on the bond durability between steel-FRP composite bars (SFCBs) and sea sand concrete in ocean environment," Construction and Building Materials, vol. 115, pp. 277-284, 2016.

[18] J. Deng and M. M. K. Lee, "A study on an innovative composite panellised wall with steel wire mesh," New Building Materials, vol. 34, no. 1, pp. 26-28, 2007 (Chinese).

[19] Y. Xie, J. Deng, and L. G. Huang, "Research on mechanical properties of basalt fiber net reinforced sea sand cementitious thin plate," in Fiber Reinforced Plastics/Composites, pp. 19-22, 2014 (Chinese).

[20] Chinese Standard, “Test methods for tensile properties of carbon fiber multifilament," GB/T3362-2005.

[21] Chinese Standard, "Glassfiber reinforced cement lightweight hollow panel for partition,” Tech. Rep. GB/T19631-2005, 2005.

[22] B. Wei, H. Cao, and S. Song, "Degradation of basalt fibre and glass fibre/epoxy resin composites in seawater," Corrosion Science, vol. 53, no. 1, pp. 426-431, 2011.

[23] B. Wei, H. Cao, and S. Song, "Environmental resistance and mechanical performance of basalt and glass fibers," Materials Science and Engineering A, vol. 527, no. 18-19, pp. 4708-4715, 2010. 

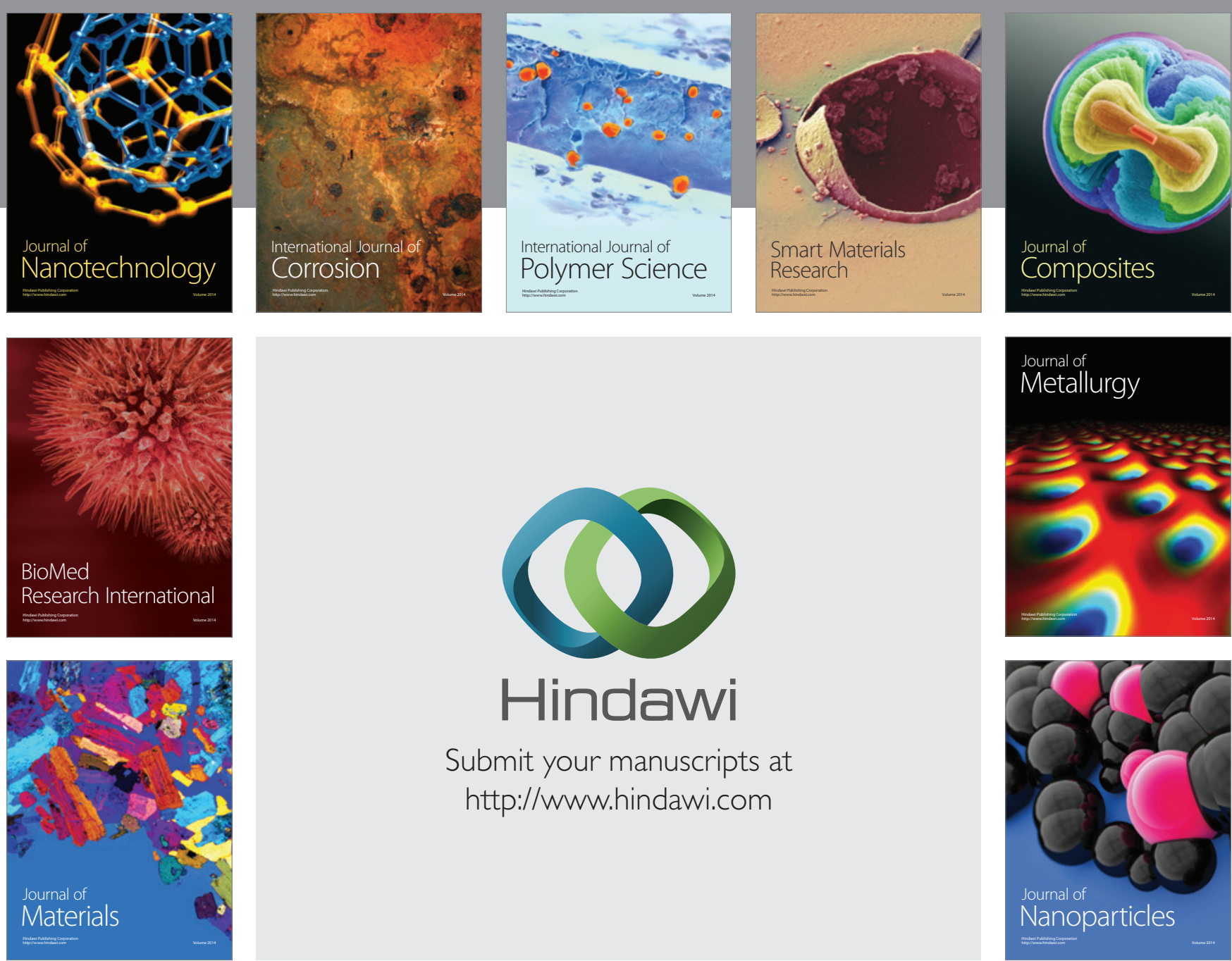

\section{Hindawi}

Submit your manuscripts at

http://www.hindawi.com

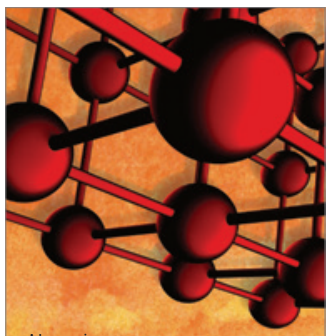

Materials Science and Engineering
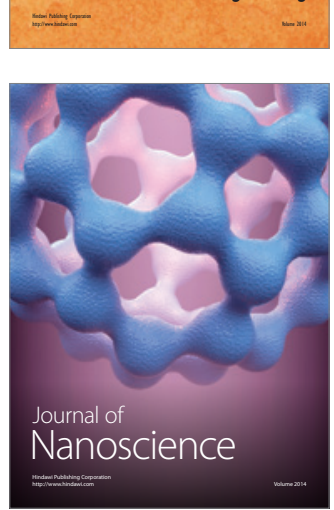
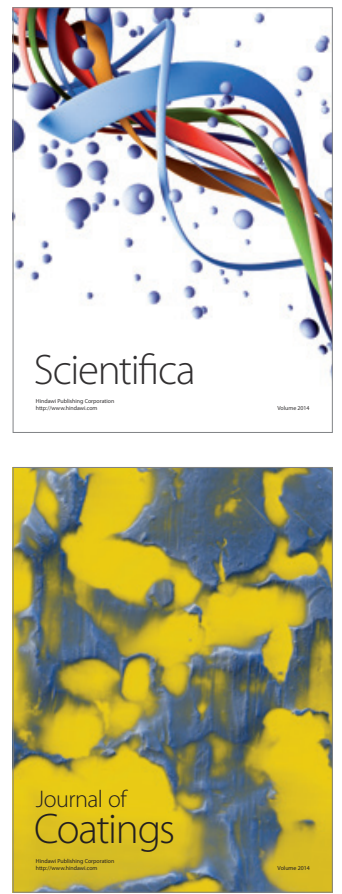
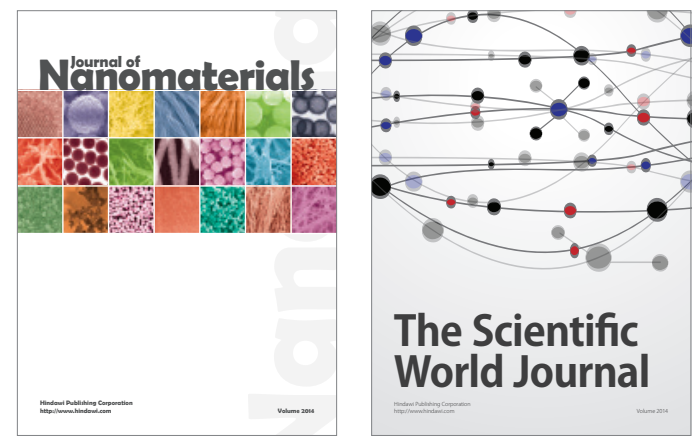

The Scientific World Journal
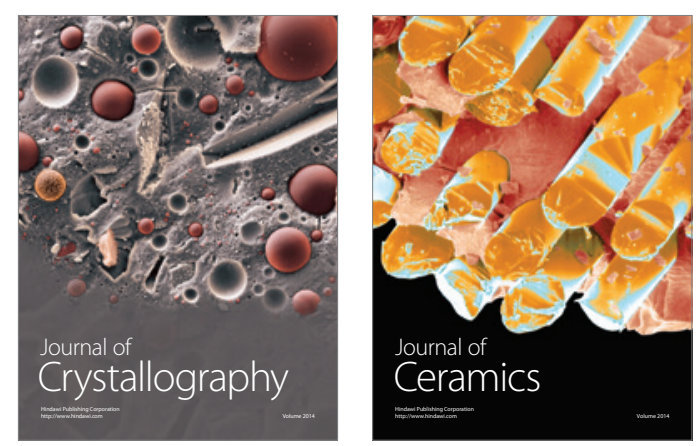
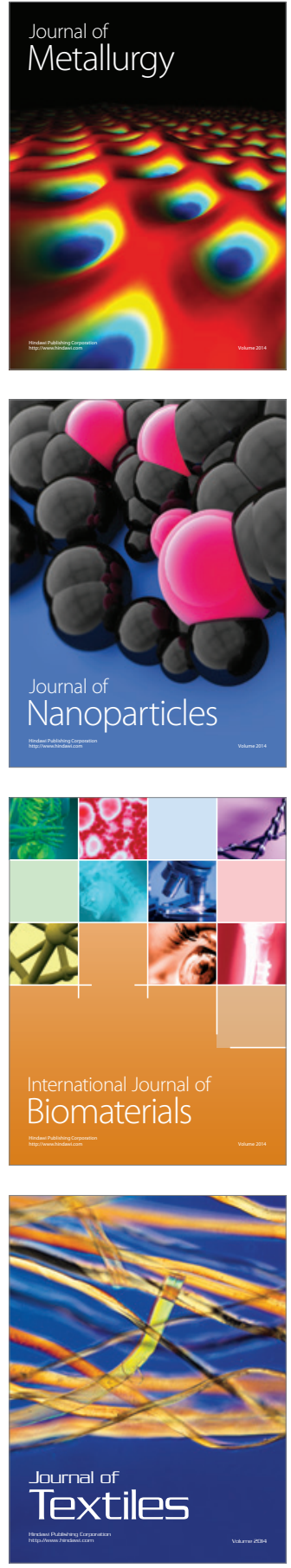